\title{
Residência médica em medicina legal: objetivos
}

\section{Medical residency in forensic medicine: objectives}

\author{
Daniel Romero Muñoz¹, Victor Alexandre Percino Gianvecchio²
}

Muñoz DR, Gianvecchio VAP. Residência médica em medicina legal: objetivos. Saúde, Ética \& Justiça. 2005;10(1/ 2):6-11.

RESUMO: A Medicina Legal é vista como especialidade que "cuida de cadáveres". Entretanto, seu campo é muito mais amplo: ela auxilia a ciência das normas, o Direito, aplicando conhecimentos médico-biológicos, para que a sociedade consiga atingir um bem maior: a justiça. Na prática cotidiana, o especialista em Medicina Legal utiliza a ciência médica para esclarecer fatos que interessam em um processo judicial ou administrativo. Para tanto, ele lança mão de conhecimentos de toda a Medicina, extrapolando, às vezes, para outras áreas das ciências biológicas. Sua área de atuação são as perícias médicas de qualquer natureza, que se constituem em elementos de prova fundamentais quando as normas (penais, civis, administrativas etc) exigem conhecimentos médicos para serem executadas. A formação de um perito médico exige, além de conhecimentos médicos e de adequadas noções de Direito, o aprendizado e o domínio de critérios específicos, que estabelecem a ligação entre os parâmetros médicos e os jurídicos. No Brasil essa formação é deficiente e deformada. O Programa de Residência Médica em Medicina Legal tem como principal objetivo formar profissionais capazes de atuarem nos diversos segmentos que compõe a Medicina Legal, visando resolver problemas da justiça na esfera pericial, como mostra o presente artigo.

DESCRITORES: Medicinal legal. Internato e residência. Prova pericial. Educação médica.

\section{INTRODUÇÃO}

A Medicina Legal é vista como especialidade que "cuida de cadáveres". Entretanto, seu campo de atuação é muito mais amplo. Ela nasceu da necessidade do Direito de ter o auxílio da Medicina para a correta aplicação das leis.
Em épocas passadas, enquanto o Direito esteve atrelado ao poder absoluto dos monarcas, estes poucas vezes se valeram de provas médicas para embasar seus julgamentos. À medida, porém, que esses grilhões foram sendo retirados e o Direito passou a nortear-se pelos ideais de liberdade,

\footnotetext{
1 Professor Titular, Responsável pela Disciplina de Medicina Legal da Faculdade de Medicina da Universidade de São Paulo. Coordenador da Residência em Medicina Legal.

2 Médico residente de Medicina Legal do Departamento de Medicina Legal, Ética Médica e Medicina Social e do Trabalho da Faculdade de Medicina da Universidade de São Paulo.

Endereço para correspondência: Prof. Dr. Daniel Romero Muñoz. Departamento de Medicina Legal, Ética Médica e Medicina Social e do Trabalho da Faculdade de Medicina da USP. Rua Teodoro Sampaio, 115 - Cerqueira César - São Paulo SP. CEP 05405-000.
} 
igualdade e fraternidade - proclamados há cerca de dois séculos pela revolução francesa - e os direitos do cidadão motivaram a maioria das revoluções nos dois últimos séculos, as avaliações médicas assumiram papel essencial na preservação dos direitos do ser humano e a atividade do médico perito tornou-se cada vez mais necessária, como meio de prova, para garantir a correta aplicação das normas.

Hoje a Medicina Legal age ou deve agir pela "aplicação dos conhecimentos Médicos e biológicos na elaboração e execução das leis que deles carecem". Ela é, segundo Buchner, a ciência do médico aplicada aos fins da ciência do Direito². É a área de sobreposição entre o campo da Medicina e o do Direito.

Desse modo, através da Medicina Legal, a Medicina presta sua colaboração para a edificação de uma sociedade mais justa, na qual as pessoas possam ter assegurados os seus direitos a uma vida digna.

A Medicina Legal, como diz Calabuig ${ }^{3}$, se insere nas disciplinas médico-sociais. Surgiu da necessidade da intervenção dos médicos, como peritos, nos órgãos de administração da Justiça. Foi se modificando e ampliando à medida que o Direito se desenvolvia. É chamada a atuar sempre que a matéria biológica se converte em substrato de normas de direito ou de disposição administrativa de qualquer índole .... O objeto da Medicina Legal se deduz de seu caráter de ciência auxiliar do Direito, o que lhe dá uma natureza eminentemente aplicativa, completada de forma harmônica com uma manifestação teórica e doutrinária. Utiliza técnicas e métodos que incorporou de campos afins ou que desenvolveu por si mesma para os casos que requerem procedimentos especiais que não são necessários em outros ramos da Medicina. Neste particular, seus métodos de estudo extrapolam o campo da medicina, abrangendo o das ciências biológicas em geral e também o das ciências sociais.

Nas palavras de Simonin ${ }^{4}$ a Medicina Legal aparece com uma tripla complexidade por sua natureza médica, seu caráter social e seu espírito jurídico. Para o médico perito atingir suas metas, não basta ter a ciência médica; é fundamental que conheça as normas a que está adstrita a perícia, que entenda "a língua do Direito", que compreenda seus objetivos e que esteja ciente da jurisprudência. Esses conhecimentos o capacitarão a entender, empregar e a aperfeiçoar os critérios médico-legais aplicáveis a cada situação.

\section{O MÉDICO PERITO}

Perito médico, quem é esse personagem ? Qual o seu papel social?
Formulamos essas perguntas a vários médicos. A maioria dos colegas desconhecia o papel e a importância do perito médico porque não sabiam o essencial: avaliar a finalidade e o alcance social do que ele faz - perícia médica - bem como das qualificações que deve ter para poder fazê-lo bem ${ }^{5}$.

Perícia médica é uma sindicância de natureza médica que visa esclarecer fatos que interessam em um processo judicial ou administrativo. É um elemento de prova fundamental quando as normas (penais, civis, administrativas etc) exigem conhecimentos médicos para serem executadas. Exemplos: $1^{\circ}$ ) No julgamento de um caso de homicídio, a primeira prova exigida é a da morte da vítima, isto é, a Justiça - para por em prática a Lei Penal - precisa que um médico faça o diagnóstico de certeza da morte da vítima, prova que é, geralmente, apresenta na forma de um laudo, elaborado após a realização da perícia necroscópica; $2^{\circ}$ ) Em um processo civil de indenização por dano físico (por exemplo, em um caso de atropelamento ou de erro médico), o juiz necessitará para embasar sua sentença, que o médico perito por ele indicado, após examinar o queixoso, esclareça as implicações jurídicas dos fatos médicos que constatar ( tais como, se o reclamante apresenta lesões ou seqüelas e se estas têm nexo causal com o acidente ou com o procedimento médico, a gravidade das mesmas do ponto de vista legal, etc); $3^{\circ}$ ) Um trabalhador brasileiro que esteja inválido para o trabalho devido a uma doença, é amparado pela legislação previdenciária que lhe garante o direito de receber salário sem trabalhar; porém, para que isto ocorra, deverá ser constituído um processo administrativo de aposentadoria por invalidez, no qual a incapacidade laborativa terá que ser comprovada através de uma perícia médica.

\section{OBJETIVO DA MEDICINA LEGAL: JUSTIÇA}

Note-se que o objetivo da Medicina é a saúde do homem 6 , tanto do ponto de vista curativo quanto do preventivo. Ao realizar essas atividades, o médico perito não está exercendo medicina curativa nem preventiva, ou seja, sua finalidade não é o tratamento nem a prevenção de doenças. Sua finalidade é mais vasta, em termos de ação social, uma vez que ele auxilia o Direito, ciência das normas que disciplinam as relações dos homens em sociedade ${ }^{7}$, cujo objetivo é a justiça. Portanto, o especialista em Medicina Legal, apesar de ser médico, não atua na área de saúde, isto é, seu objetivo não é a saúde do homem, mas a preservação dos direitos do ser humano. Ou seja, ele atua na área da justiça.

Na prática, a ação do perito médico consiste 
em realizar investigações técnicas (exames clínico, laboratorial, radiológico, etc, vistoria de local e outras), na busca de fatos de natureza médica, que possam esclarecer questões normativas que interessam em um procedimento judicial (processo civil, criminal, trabalhista, etc) ou administrativo (sindicância, por exemplo). Essas questões, geralmente, têm por intuito, verificar se o caso enquadra-se em determinadas normas (leis, regulamentos, etc) vigentes. Para realizar bem suas atividades, ele tem que estar em contínuo aprimoramento, tanto do ponto de vista médico quanto do jurídico, pois à medida que o Direito evolui e surgem novas legislações e estatutos, haverá necessidade de novos tipos de perícias no momento de julgar um caso por esses dispositivos legais. As leis previdenciárias e trabalhistas, por exemplo, inexistiam no Brasil no começo do século XX e, portanto, as perícias dessa natureza só apareceram quando o Direito incursionou por essas áreas.

\section{A FORMAÇÃO DO ESPECIALISTA EM MEDICINA LEGAL}

Para atingir sua meta, não basta ao médico perito conhecer a ciência médica; é fundamental que entenda "a língua do Direito" (para poder assimilar o espírito da lei e não apenas a sua letra), que conheça as normas a que está adstrita a perícia, que compreenda seus objetivos jurídicos e que esteja ciente da jurisprudência, isto é, da interpretação dada pelos juizes a cada peculiaridade da lei, nos casos que julgam. Esses conhecimentos o capacitarão a entender, empregar e até mesmo aperfeiçoar os critérios médicolegais aplicáveis a cada situação pericial. Sem esses requisitos, há uma grande possibilidade dele de servir a Justiça em vez de auxiliá-la.

A formação de um perito médico exige - além de conhecimentos médicos e de adequadas noções de Direito - o aprendizado e o domínio desses critérios específicos, que estabelecem a ligação entre os parâmetros médicos (diagnósticos, terapêuticos e preventivos) e os jurídicos. No Brasil, essa formação é deficiente e deformada. Um dos fatores é a carga horária de Medicina Legal nos cursos de graduação em Medicina (onde é disciplina obrigatória). Essa carga, além de exígua, contempla, na maioria das escolas, apenas a parte criminal, o que faz com que o médico, ao formar-se, lembre apenas da parte sensacional da Medicina Legal: as aulas práticas no IML, principalmente as de necropsia. Em termos de pós-graduação lato sensu, os programas são escassos, tanto que em São Paulo só há um curso universitário de especialização na área, ministrado pela Faculdade de Medicina da USP. A residência em Medicina Legal visa mudar esse panorama.

\section{OBJETIVOS DA RESIDÊNCIA MÉDICA EM MEDICINA LEGAL}

O principal objetivo da Residência em Medicina Legal é a formação de especialistas de alto nível para suprir a carência de profissionais gabaritados nessa área médica, ou seja, formar um tipo de profissional capaz de atuar nos diversos segmentos que compõe a Medicina Legal, visando resolver problemas da justiça na esfera pericial.

Um desses problemas é a deficiência de peritos médicos competentes, com capacidade para realizar perícias que envolvam mais de uma especialidade médica. Tomemos como exemplo o seguinte caso: $O$ vendedor de uma grande empresa de confecções foi atropelado quando "corria a praça de vendas" que Ihe foi designada. Sofreu fratura de tíbia, rotura de baço e traumatismo crânio-encefálico; como era portador de hipertensão arterial e problema cardíaco associado, teve descompensação cardio-circulatória; por fim apresentou distúrbio emocional. Após a alta teve que prestar depoimento na delegacia, onde havia sido aberto o inquérito policial, sendo encaminhado para perícia de lesões corporais no IML. Como o fato configura acidente de trabalho, foi submetido à perícia acidentária do INSS (seguradora estatal dos acidentes de trabalho no Brasil); inconformado com o resultado da mesma, ingressou com ação na justiça, sendo designada, pelo juiz da vara acidentária, perícia judicial de acidente de trabalho. Como tinha um seguro de acidente pessoal, comunicou, à empresa seguradora, o acidente e as lesões sofridas, com vistas a receber a indenização a que julga fazer jus. A seguradora o encaminhou para um perito de sua confiança, para ser submetido à perícia securitária. Por último, ele ingressou com uma ação cível contra o atropelante, requerendo indenização por perdas e danos, acumulada com danos morais. Para a realização das perícias cíveis, o juiz da vara cível nomeou um ortopedista para realizar perícia referente à fratura de tíbia, um cirurgião geral para a da rotura de baço, um neurologista para a do TCE, um cardiologista para a da descompensação circulatória e um psiquiatra para a do distúrbio emocional. Ao final ele recebe cinco laudos, cada um com uma conclusão diferente e, pior, sem o embasamento adequado pela deficiência de formação na área médico-legal. Esses laudos criam sérios problemas para a Justiça, uma vez que, além de não fornecerem elementos técnicos fundamentados em critérios médico-legais que 
permitam enquadrar o caso na jurisprudência e na legislação pertinentes, de modo a dar o substrato técnico requerido a uma sentença segura e justa, atrasam o andamento do processo, muitas vezes por vários anos, pela demanda cotas e quesitos para esclarecimentos, novas perícias etc.

A residência de medicina legal visa à formação de perito capaz de avaliar esse tipo de caso como um todo, ou seja, realizar uma perícia que englobe a fratura de tíbia, a rotura de baço, o TCE, a descompensação cardiocirculatória e o distúrbio emocional, emitindo um só laudo, que forneça à Justiça os elementos que ela necessita, embasados em critérios técnicos e médico-legais adequados ao caso.

\section{PROGRAMA DA RESIDÊNCIA DE MEDICINA LEGAL}

O único Programa de Residência Médica em Medicina Legal aprovado, até o momento, pela Comissão Nacional de Residência Médica (CNRM) do Ministério da Educação é o do Departamento de Medicina Legal, Ética Médica, Medicina Social e do Trabalho da Faculdade de Medicina da USP, que começou a ser desenvolvido em 2004.

O programa tem a duração de três anos e duas vagas por ano credenciadas pela CNRM. A Fundação de Aprimoramento de Pessoal (FUNDAP), entretanto, disponibilizou apenas uma bolsa por ano para a residência de Medicina Legal, motivo pelo qual tivemos apenas um residente em 2004. Neste ano, porém, conseguiu-se uma segunda bolsa, doada por empresa particular, de modo que, em 2005, há dois residentes de primeiro ano.

A primeira etapa da residência, que dura cerca de um ano e três meses, é composta, basicamente, por estágios hospitalares, desenvolvidos no Hospital das Clínicas da Faculdade de Medicina da Universidade de São Paulo (HCFMUSP). Essa fase foi estruturada com base nos programas de residência médica que são tradicionalmente desenvolvidos nesse hospital escola, contando com a colaboração dos coordenadores dos mesmos. Esta etapa está centrada no treinamento da propedêutica utilizada pelas várias especialidades, bem como na discussão das suas condutas específicas, podendo ser desenvolvida nos setores de urgência/emergência, enfermarias e/ou ambulatórios.

O treinamento em serviço é feito através de estágio nos seguintes serviços:

$>$ Clínica Médica Geral: atendimento no AGD (Ambulatório Geral e Didático) da clínica médica;
$>$ Pneumologia: atendimento nos ambulatórios e enfermaria de pneumologia;

$>$ Reumatologia: atendimento nos ambulatórios da Reumatologia;

$>$ Cardiologia: atendimento de casos no Pronto Atendimento e no ambulatório de triagem do INCOR (Instituto do Coração do Hospital das Clínicas), discussões didáticas de Eletrocardiograma e Radiografias com as equipes que laudam estes exames no INCOR;

$>$ Pronto Socorro do INCOR: atendimento de pacientes com urgências/emergências cardiológicas que procuram o PS INCOR;

DPronto Socorro da Clínica Médica: atendimento de pacientes que dão entrada no PSMHC (Pronto Socorro Médico do Hospital das Clínicas), inclusive na sala de emergências clínicas;

> UTI da Clínica Médica: acompanhamento (evolução) de pacientes internados na UTI, visitas e discussões dos casos;

$>$ Neurologia: atendimento de pacientes encaminhados para avaliação ao PSNHC (Pronto Socorro da Neurologia do Hospital das Clínicas), onde é realizado exame neurológico completo e exames complementares;

$>$ Cirurgia Geral: atendimento de pacientes que dão entrada no PSCHC (Pronto Socorro de Cirurgia do Hospital das Clínicas), inclusive na sala de trauma;

$>$ Neurocirurgia: atendimento de pacientes encaminhados ao PSNCHC (Pronto Socorro Neurocirurgia do Hospital das Clínicas) para avaliação, acompanhamento e cirurgia neurológica;

$>$ Ortopedia: atendimento de pacientes nos ambulatórios de diversas especialidades (mão, ombro, joelho, coluna, etc) e no Pronto Socorro do IOTHC (Instituto de Ortopedia e Traumatologia do Hospital das Clínicas);

$>$ Anestesiologia: acompanhamento do procedimento anestésico nas diversas salas cirúrgicas (eletivas, emergências, obstétricas, ortopédicas, infantil), acompanhamento no ambulatório de avaliação pré-anestésica, acompanhamento dos pacientes no RPA (recuperação pós-anestésica) nos centros cirúrgicos do Hospital das Clínicas;

- Especialidades Cirúrgicas: atendimento nos ambulatórios de:

- Cirurgia Plástica (queimados, mama, reparadora, obesidade mórbida) e na 
enfermaria de queimados;

- Urologia (impotências e infertilidade);

- Otorrinolaringologia (ORL ocupacional);

- Oftalmologia (PS oftalmologia) e

- Coloproctologia (patologias orificiais).

$>$ Ginecologia: atendimento de pacientes nos ambulatórios e no Pronto Socorro da Ginecologia;

$>$ Obstetrícia: atendimento de pacientes nos ambulatórios da Obstetrícia e na Sala de Parto (normal e cesárea).

$>$ Pediatria

- Berçário: evolução de pacientes internados no Berçário do $\mathrm{HC}$, visitas no Berçário, acompanhamento do atendimento do $\mathrm{RN}$ (recém nascidos) na Sala de Parto;

- Pronto-Socorro: atendimento de pacientes no Pronto Socorro do ICr (Instituto da Criança), visitas aos pacientes internados no PS.

$>$ Psiquiatria: atendimentos nos ambulatórios de Psiquiatria do IPq (Instituto de Psiquiatria) e na interconsultas (consultas solicitadas à psiquiatria pelas outras especialidades nos pacientes internados no $\mathrm{HC}$ ), além de visita à enfermaria do IPq.

A segunda e terceira fases (segundo e terceiro anos) compreendem o treinamento nos seguintes serviços:

> Ambulatório Saúde Ocupacional (segundo ano): atendimento de pacientes nos ambulatórios do SSOHC (Serviço de Saúde Ocupacional do Hospital das Clínicas);

$>$ Ambulatório Grandes Empresas (segundo ano): acompanhamento do serviço de saúde ocupacional da empresa Daimler-Chrysler do Brasil, incluindo o atendimento ambulatorial de PCMSO (Programa de Controle Médico em Saúde Ocupacional), acompanhamento de visitas aos postos de trabalho na fábrica, acompanhamento da avaliação ergonômica às máquinas, acompanhamento de perícias realizadas na empresa;

Reabilitação (segundo ano): atendimento de pacientes acompanhados nos diversos ambulatórios da DMRHC (Divisão de Medicina de Reabilitação do Hospital das Clínicas) na avaliação de incapacidades;

$>$ Perícias Cíveis (segundo ano): acompanhamento de perícias cíveis realizadas no IMESC (Instituto de Medicina Social e Criminologia);

Perícias Acidentárias (segundo ano): acompanhamento de perícias de acidente do trabalho realizadas no Setor de Perícias Acidentárias das VAT (Varas de Acidentes do Trabalho) do Foro de São Paulo;
$>$ Perícias Administrativas (segundo ano): acompanhamento das perícias administrativas (afastamento do trabalho, aposentadorias etc) em funcionários públicos, realizadas no DPME (Departamento de Perícias Médicas do Estado de São Paulo);

> Perícias Previdenciárias (segundo ano): acompanhamento de perícias previdenciárias (contra o INSS) realizadas no JEF (Juizado Especial Federal) de São Paulo;

$>$ Laboratório Médico-Legal (segundo ano e terceiro ano): acompanhamento de procedimentos realizados em exames de DNA para avaliação de vínculo genético (paternidade/maternidade) no IMESC e no laboratório do IOF (Instituto Oscar Freire); outros exames laboratoriais forenses realizados no IOF (manchas de sangue, esperma etc);

$>$ Antropologia forense (terceiro ano): acompanhamento de perícias antropológicas (exame de ossadas, restos humanos, carbonizados etc) realizadas no IML (Instituto Médico-Legal) e IOF, com finalidade identificatória médico-legal;

> Toxicologia forense (terceiro ano): exames de toxicologia forense (apreensão de entorpecentes e casos de embriaguez alcoólica e envenenamento) realizados no IML e IOF;

$>$ Laboratório de Criminalística (terceiro ano): exames periciais de balística, fonética e outros realizados no IC (Instituto de Criminalística);

$>$ Auditorias Médicas (terceiro ano): acompanhamento de auditorias médicas HCFMUSP;

Patologia - Necrópsia (terceiro ano): realização de necrópsias anátomo-patológicas no SVO (Serviço de Verificação de Óbitos - Departamento de Patologia - FMUSP);

> Clínica Médico-Legal (primeiro e terceiro ano): acompanhamento de perícias de lesão corporal no IML;

$>$ Sexologia Forense (terceiro ano): acompanhamento de perícias de sexologia forense (estupro, atentado ao pudor, abortamento etc) no Bem Me Quer, serviço do IML sediado no Hospital Pérola Byton;

> Tanatologia Forense - Necroscopia (terceiro ano): acompanhamento de perícias necroscópicas (necrópsias médico-legais) no IML;

> Psicopatologia Forense (terceiro ano): acompanhamento de perícias de psicopatologia forense no IPq HCFMUSP e no IOF.

A parte teórica, desenvolvida paralelamente aos 
estágios práticos, inclui bioética, metodologia científica, além de cursos de medicina legal e de medicina do trabalho.

\section{EPÍLOGO}

A exclamação de alguns colegas é que estamos querendo formar um super médico. Não é esse o escopo da residência em Medicina Legal. $O$ intuito é formar um bom "clínico geral" para a área pericial. Esse perito tem que ter formação médica ampla para poder avaliar casos em qualquer área da medicina, mas quando tiver dúvidas ou o caso exigir conhecimentos especializados que vão além da sua competência, fará o que faz qualquer clínico geral nessa circunstância: pede uma consulta ao especialista, o qual, em casos médicolegais, emite um parecer especializado, que o perito anexa ao seu laudo. Este, porém, utiliza o conteúdo do parecer em sua avaliação, integrando-o no seu laudo e servindo-se dele para a conclusão pericial do caso. Por outro lado, se o caso requer avaliação de uma única especialidade médica e/ou trata-se de uma perícia ultra especializada, o nosso médico perito terá o discernimento de expor a situação ao juiz e sugerir a nomeação de um especialista da área. Por uma questão de bom senso e pelo que foi acima exposto, este especialista, além de atuar na sua área específica, deverá ter também conhecimentos de Medicina Legal para atuar no processo com a competência que se exige de um perito.

Muñoz DR, Gianvecchio VAP. Medical residency in forensic medicine: objectives. Saúde, Ética \& Justiça. 2005;10(1/ 2):6-11.

ABSTRACT: Legal Medicine is usually seen as a specialty that only "deals with cadavers"; however, the field entails much more than this: it aids in the science of norms, law, applying medical-biological knowledge, such that society can greatly improve in relation to justice. In daily practice, a specialist in legal medicine uses medical science to clarify facts that are of interest in judicial or administrative cases. Thus, it utilizes all aspects of medical knowledge, extrapolating, at times, to other areas of biological science. It functions as medical expertise of any nature that constitutes elements of proof that are fundamental, when the norms (penal, civil, administrative etc.) require medical knowledge to be established. The education of a medical expert requires, besides medical knowledge and an adequate understanding of the law, apprenticeship training and the domain of specific criteria, that establishes a link between medical and judicial parameters. In Brazil, this education is lacking and deformed. The principal objective of the residence program in Legal Medicine is to educate a professional capable of acting in the diverse segments that make up Legal Medicine, aiming to resolve judicial problems, in the area of medical expertise, as is shown in the present article.

KEY WORDS: Forensic medicine. Internship and residency. Expert testimony. Education, medical.

\section{REFERÊNCIAS}

1. Fávero F. Medicina legal. São Paulo: Martins; 1973.

2. França GV. Medicina legal. Rio de Janeiro: Guanabara Koogan; 1995.

3. Calabuig JAG. Medicina legal y toxicología. Barcelona: Masson; 1998.

4. Simonin C. Medicina legal judicial. Barcelona, Editorial JIMS; 1973.
5. Muñoz DR. O perito médico: Quem é esse personagem? O que ele faz? J CREMESP. 1998;125:6.

6. Conselho Federal de Medicina. Código de ética médica. Resolução CFM 1246/88. 2 ${ }^{\underline{a}}$ ed. Brasília: Tablóide; 1990.

7. Holanda $A B$. Novo dicionário da língua portuguesa. Rio de Janeiro: Nova Fronteira; 1975. 